\title{
Did Gig Economy Change Ways of Work? Evidence from American Time Use Survey
}

\author{
Rao Rao
}

Student, China

\begin{abstract}
.
The rise of the "gig economy" has become an important trend in the labour market, and economists have recently started examining its macroeconomic impacts. Based on the aggregate time-series data from American Time Use Survey from 2007 to 2017, this paper explores whether the gig economy has led to more flexible work arrangement and work-time allocation in three dimensions: (1) part-time/full-time; (2) work at home/in the workplace; (3) wage-salary work/self-employed. It makes three hypotheses about the impacts of the rise of the gig economy on people's working styles and places, with the development of the gig economy, Americans are more willing and have more opportunities to have a part-time job rather than a full-time job, the citizens prefer to work from home compared to at fixed workplaces, and people tend to be more self-employed. This paper suggests that there is a shift toward work-flexibility in terms of location in the United States over the past decade, i.e. people tend to work more at home versus at workplace, a trend mostly obvious among women, a full-time job and wage-salary workers. In contrast, the evidence for a shift toward part-time job and self-employment are less conclusive.
\end{abstract}

Keywords: Change in American workers working; Flexible working styles; Gig Economy; Time use; Work from home 


\section{International Academic Conference on Management \& Economics}

\section{Introduction}

Over the past ten years, the rapid rise and development of the mobile internet have facilitated the emergence of what is so-called gig economy. The prevalence of the gig economy has also led to the creation of new occupations, such as Uber drivers, Airbnb hosts and online video bloggers. It has also attracted the attention of many media and economists. According to the report by The Economists on 22 October, 2015, due to the recession of the British economy in 2008, many enterprises laid off their workers, which may lead to a surge in the number of self-employed businesses in Britain; however, the figures show that the number of self-employed people in the UK was still 700,000 higher in 2014 than in 2008, though there was a fall in unemployment, and one of the reasons behind this situation is the rise of the gig economy.

Media and academia vary in their definitions of the gig economy. For instance, Freedland and Prassl (2017) name it as the on-demand economy, which means producing and operating activities around the actual needs of the labor force. According to Gardiner (2015), the gig economy is the activity of earning or supplementing income by trading personal goods and services online. Regardless of the specific definition, what is clear is that the gig economy is characterized by a larger number of freelancers, part-time workers and temporary workers than the traditional economy. One of the most significant impacts is that people have more flexible ways of working in terms of location, schedule and contractual relationship.

The ride-hitching is one of the notable examples of the gig economy is. In the U.S., for instance, the past 5-6 years saw a rapid rise of companies such as Uber. Uber was founded in 2009 , just as the gig economy began to take off.

Figure 1: The Rise of The Gig Economy

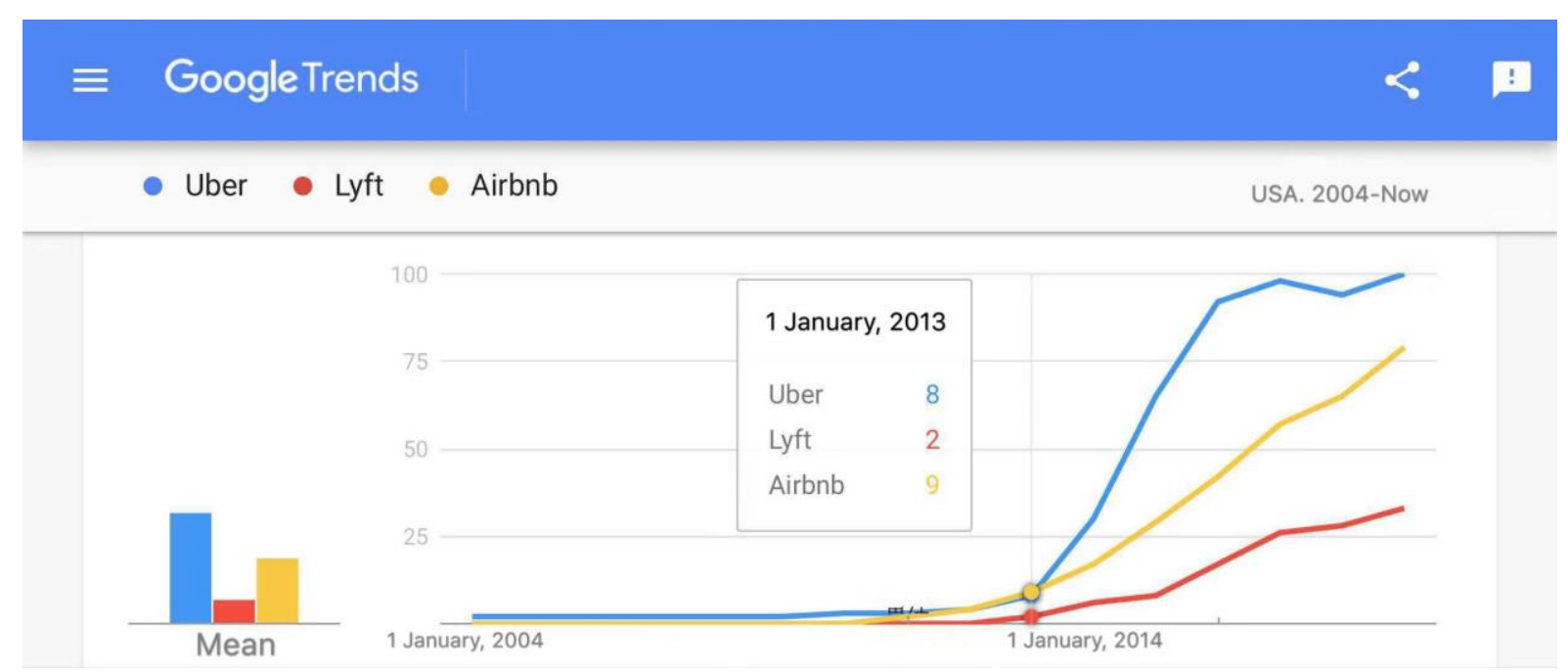

Source: Figure is from Google Trends.

Figure 1 represents the Google Trends of three example companies, Uber, Lyft and Airbnb since 2004. It vividly illustrates the rapid rise of gig economies in recent 5 years. Specifically, 


\section{International Academic Conference on Management \& Economics}

8 - 10 November, 2019

Oxford, United Kingdom

Uber has been gaining popularity over time since around 2013 and other two companies followed a similar trend. This phenomenon is consistent with the idea of this paper since the gig economy is indeed emerged in recent years and gradually developed.

Figure 2: The Rise of The Gig Economy

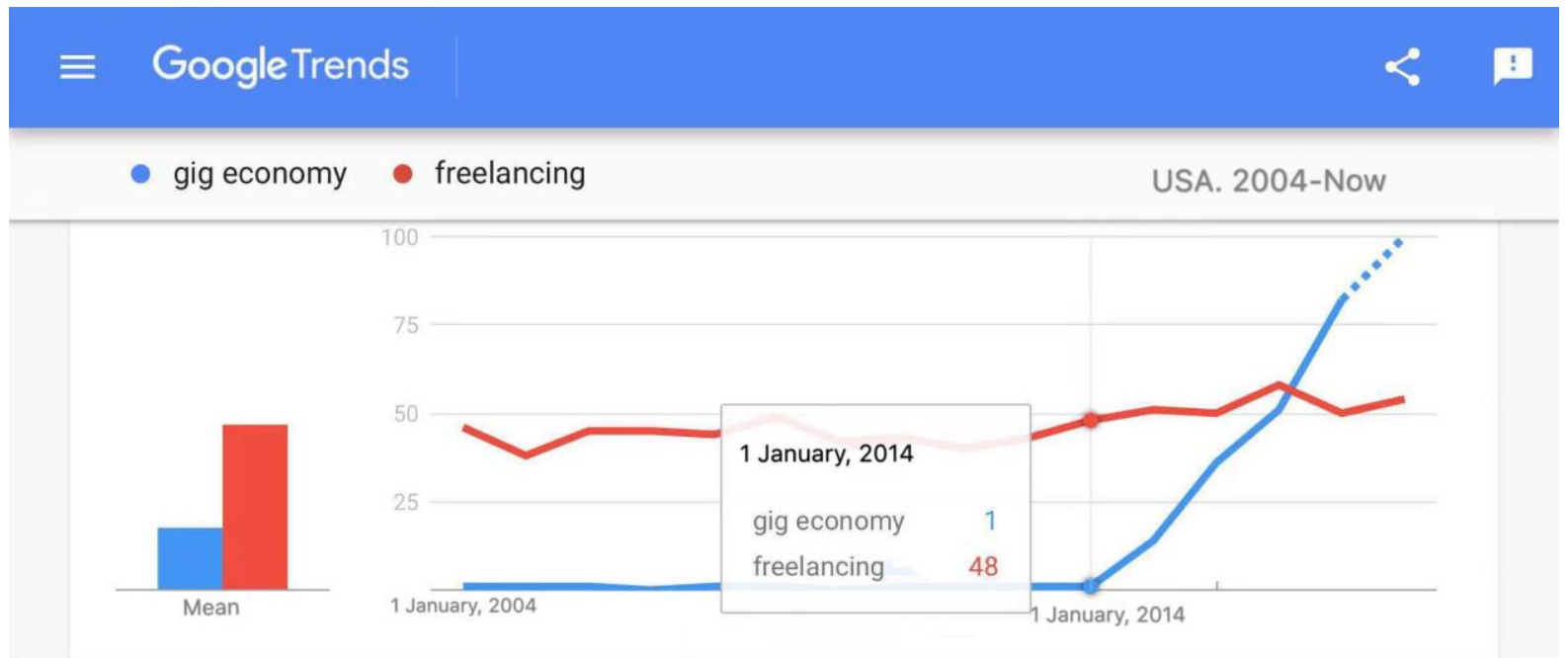

Source: Figure is from Google Trends.

The direct search trend of the word "gig economy" paints a similar picture. According to Figure 2, it has been shown that the gig economy has been developing rapidly since 2014, and with the development of the gig economy, the popularity of freelancers has also been increasing, although the extent of the increase is relatively small, it generally presents an upward trend after over the period. Figure 2 has proved that the gig economy emerged in 2014, which may result in the rise of the popularity of working from home. Figure 3 thus looks into the trends of work from home directly. There is a gradual increase in the popularity of the term, which is consistent with the idea of this paper. As we will show later, we do find evidence of a shift from work at the workplace to at home that is likely to be facilitated by the gig economy.

The rise of ride-hitching business illustrates a rising trend of the new form of the economy across different sectors. In light of this, this paper aims at understanding whether the rise of the gig economy changed people's work style. It is important to macroeconomists as new ways of work may result in different mechanisms of macroeconomics. For the following reasons.

1. The gig economy may affect how people measure and count employment and unemployment. 


\section{International Academic Conference on Management \& Economics}

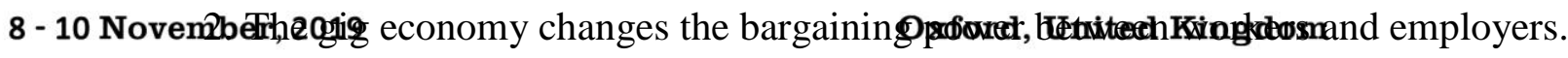

3. The gig economy enables people who used to have limited access to larbor market to join now.

Figure 3: The Rise of The Gig economy

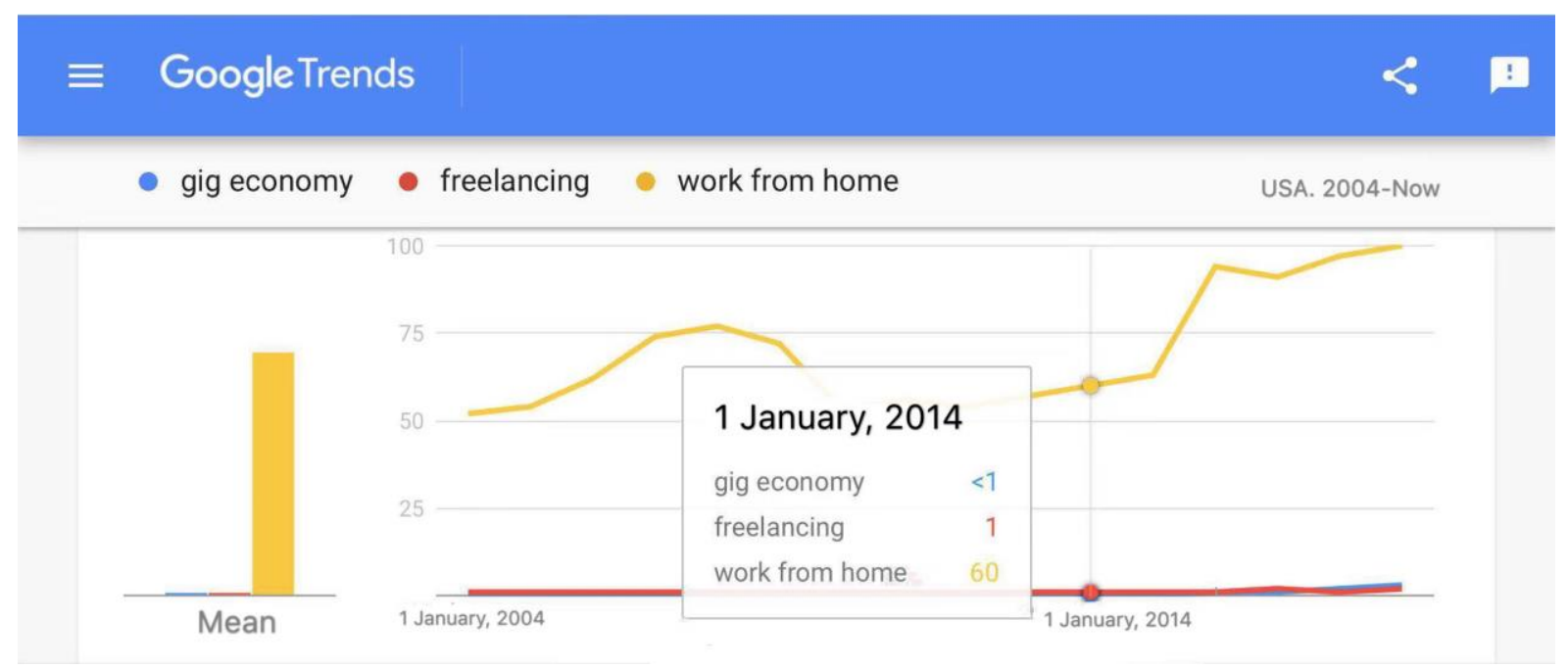

Source: Data is from Google Trends

The paper analyzes the trend of work-flexibility indicated by the time allocation of labor forces in the U.S. It examines the average trends for the aggregate labor force as well as different subgroups are broken down by gender and other characteristics of the work. In addition, the paper focuses on three dimensions through which the gig economy affects work flexibility. To put it simply, we define them as the employment status, location of work and the type of work, respectively. Employment status refers to the distinction between full-time and part-time works. Location refers to the work at the workplace and home. Type of work refers to wage workers versus self-employed workers.

According to the data given by American Time Use Survey, it is shown that among the three criteria of the work flexibility, the location of work is one through which the way of work has changed most significantly from 2007 to 2017, which can be further associated with the rise of the gig economy. On one hand, the relative time devoted to work at home increase relative to at the workplace, especially for women, full-time workers and wage workers. On the other hand, within the group that work from home, there is a rise in full-time works and wage-salary jobs available.

There are three directions of literature relevant to this paper. First, a few work attempt to go beyond the traditional statistics to measure the gig economy. For instance, Abraham et al. (2018) compares household data with administrative surveys on the hours of gig jobs, and compares people who had self-employment activities on household and administrative data and 


\section{International Academic Conference on Management \& Economics}

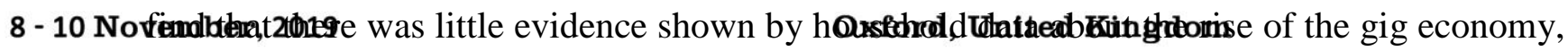
while the administrative data provided a considerable growth of the gig economy.

Second, the paper is related to the research focus on the macroeconomic implications of the gig economy. For instance, Duca (2018) showed that the rise of the gig economy has reduced the unemployment rate and the sensitivity of inflation to unemployment rate changes, along with the reduction of the bargaining power of workers in labor markets. Farrell and Greig (2016) discussed the fluctuation of personal income in the United States and the size and development of online platforms in their paper. Robles and McGee (2016) elaborated on the development of the zero-employment economy over time, the shift in the way of working, from traditional methods and formal working methods to paid informal work methods in their paper.

Third, Goldschmidt and Schmieder (2017) discussed the development of the German outsourcing business in the past three decades and showed how the business developed from the very beginning to the peak and then slowed down.

Although many economists have made a lot of studies on the gig economy, such as the responses to the differences in income due to the rise of the gig economy around the world. However, this paper is devoted to answering the macro response of the United States to the development of gig economy, and differentiating different gender, workplace, employment status and type of work. It turns out that as the gig economy has grown, people who work from home spend more time working than those who work in the workplace, and more frequently work full time.

\section{Hypothesis}

There are many ways via which the gig economy makes the work arrangement more flexible. This paper focuses on three dimensions: the employment status, the location, the type of work. With respect to the employment status (part- time/full-time), people tend to think a part-time job is more flexible than a full-time job because a part-time job is not required to stay in a certain place all the time and workers can choose their own suitable time to work. In the second dimension, working from home implies more flexibility than working in the workplace, especially for women with families because working from home provides them more freedom and allows them to take care of their families. In the third dimension, self-employed workers can control their own time well since they do not have to listen to many leaders. This paper proposes three hypotheses based on the three variables.

First, it is possible that with the development of the gig economy, people are more willing and have more opportunities to take part in a part-time job compared to a full-time job. In reality, some enterprises provide part- time jobs now, such as Uber, which has been booming in recent years. Many people choose to use Uber other than taxi when they go out.

Meanwhile, many people choose to be an Uber driver and earn extra money by offering services to customers in their spare time. It is thought that the rise of Uber is due to the rise of the gig economy since they happened at a similar time. To prove that whether it is true people tend to prefer to take a part-time job to a full-time job is one of the purposes of the paper.

The second hypothesis is that people are more willing and have more opportunities to work from home. People don't have to go to the workplace to work, they can work directly from 


\section{International Academic Conference on Management \& Economics}

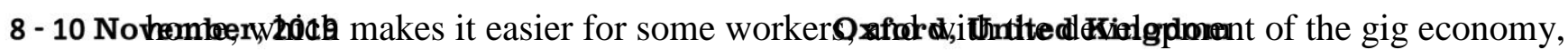
there may be more jobs available for those workers to choose from. The real-life example is Amazon, which provides a platform for sellers and buyers to trade. The sellers can make money at home, which is preferable for them. So it is assumed that people are more willing to work at home compared to work at workplace since Amazon is getting more and more popular.

People tend to be more self-employed is the third hypothesis. Each plat- form provides many different opportunities, and the business opportunities in life increase, so that people can choose what they are interested in and start their own business. The video bloggers on Youtube are good examples: they are self-employed that recording the videos by themselves could earn money. In addition, Youtube in recent years has seen visible progress and development, more and more users as a sideline or even the main business, it is true that many users get a high income.

Since the focus of the paper is if the rise of the gig economy has affected the work arrangement, ideally, we should have directly looked into the relationship between our indicators of work flexibility with some measures of penetration of gig economy. However, this paper directly looks at the time trend of these indicators by assuming that the expansion of the gig economy is consistent over the time period.

\section{Empirical Results (TNR 14pt., bold)}

\subsection{Data}

All the data this paper used came from the Bureau of Labor Statistics, from 2007 to 2017. American Time Use Survey collected labor data since January 2003, and it categorizes labor into many groups to help the users to search the data more easily and in detail. ATUS collected data using a telephone interview, a 24-hour diary that started at 4 a.m. the day before and ended at the same time the next day. For each activity, the census bureau interviewer asked respondents how long the activity lasted, and for most of each activities surveyed, the interviewer will also ask the participants who accompanied them during the activity and where the activity was took place.

According to American Time Use survey, those people who work for profits in their own businesses are called self-employed persons, people who work at least 35 hours a week are labeled as full-time workers, and those workers receiving salary or wage periodical are a

wage or salary workers. All of the categories are for the workers working at both public and private sectors.

In this paper, gender, education, employment status, location of work and type of work are directly available in the survey.

\subsection{Hypothesis 1: Employment status shift from full- time to part-time.}




\section{International Academic Conference on Management \& Economics}

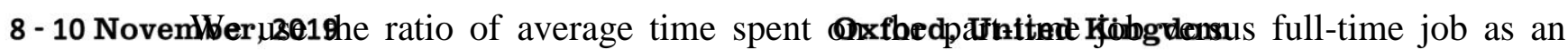
indicator of work flexibility in terms of employment status.

As shown in figure 4, there is no significant change in the trend of the relative hours of part-time works of the whole population, though it experienced a wild fluctuation from 2011 to 2015. There are several reasons that could explain why there is no noticeable trend as originally speculated. One of the most important reasons has to do with the definitions of part-time workers and full-time workers. According to the ATUS, work is categorized as part- time as long as the total work hour is less than 35 hours a week, even though this kind of work may fall into part-time for the concern of this paper. For instance, it is totally possible that a Uber driver works more than the bench- mark. Another reason is that the gig economy has different forms of labor, one of which is a mix of full-time and temporary workers, known as mixed labor (Dong and Ibrahim (2017)). This may also explain the relative change in the hours of part-time workers in different years.

Figure 4: Hypothesis 1: Aggregate Trend

- Employed part-time works/ Employed full-time works

0.7

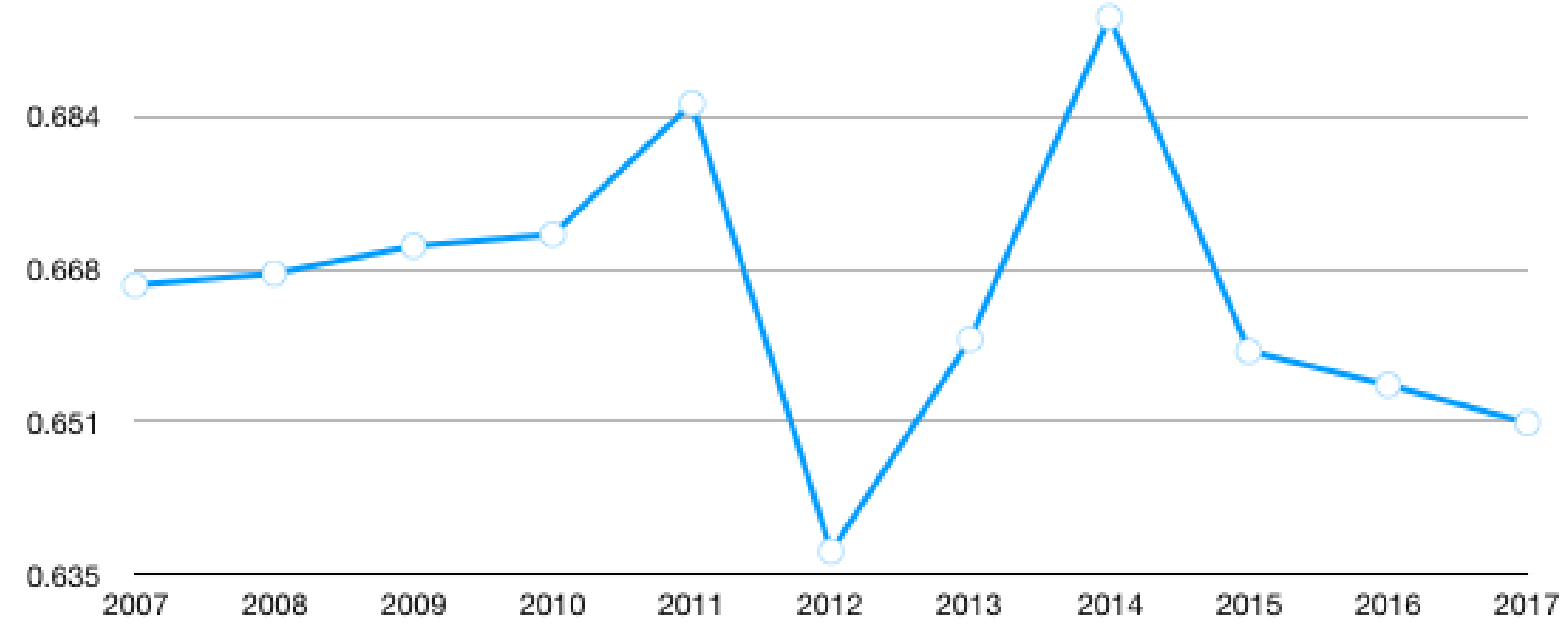

Source: Data is from Data is from American Time Use Survey.

Since there is no noticeable trend for the whole population, as the next step, I compare the difference between men and women. The purpose of looking at male and female separately is to see whether there is no obvious trend for the whole population is due to the offsetting impact of male and female. And this paper believes that women are more

likely to be affected by the development of the gig economy because they need to take care of their families, and considering they may be more willing to take a part-time job when they are pregnant. Therefore, by observing different data of different gender, it is needed to see whether the ratio has increased for women, in other words, whether the figure supports the hypothesis. However, according to figure 5, the trends for men and women were similar that there was no monotone trend for both genders. If any, women seem to work more in a full-time job in recent five years than in the past. 


\section{International Academic Conference on Management \& Economics}

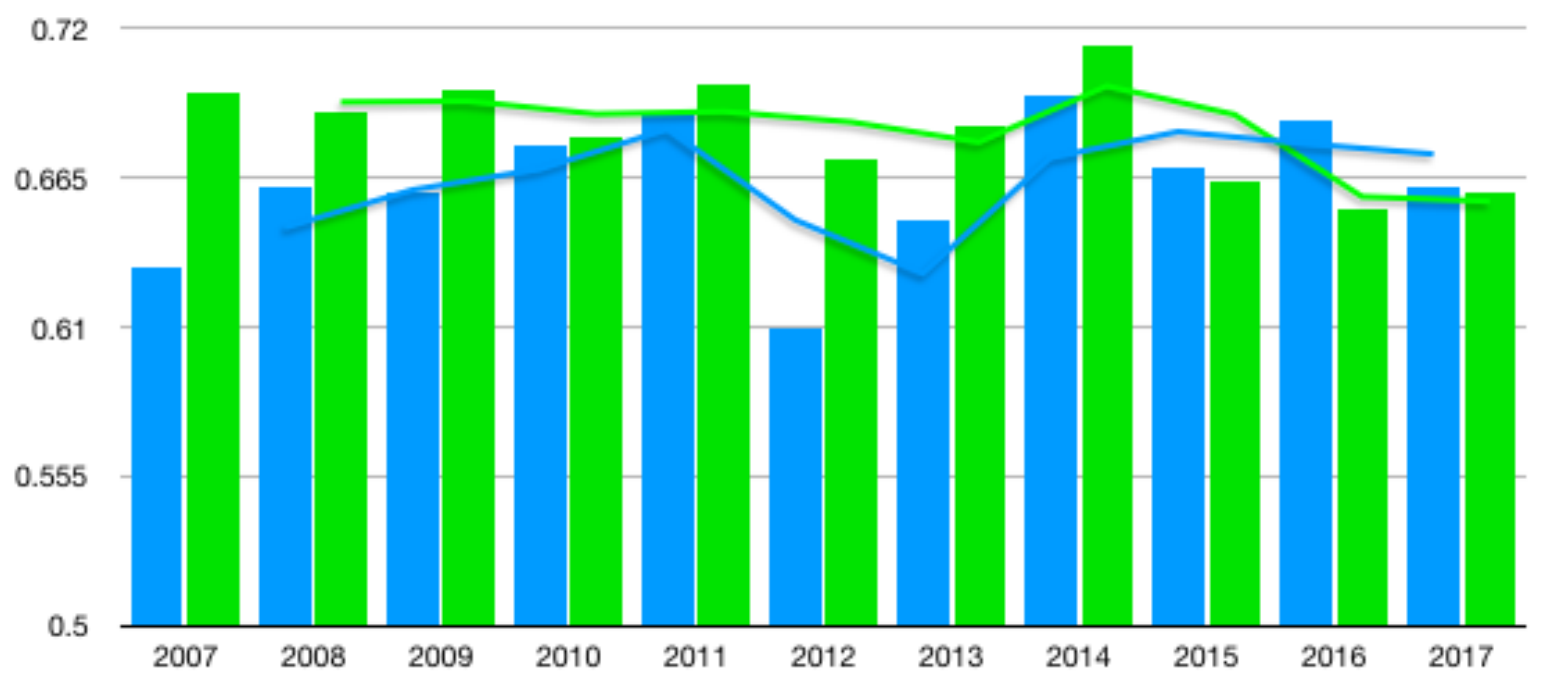

Source: Data is from Data is from American Time Use Survey.

A further breakdown of the population by both gender and location of work is shown in figure 6. It separately plots the part-time/full-time ratio of each gender and each place of work. This is important since locations of work is another variable worth considering with respect to the nature of work, and the impacts of the gig economy may affect the time allocation jointly through location and employment status. If the amount of time spent working at home increases and the amount of time spent working at the workplace drops, it may be the evidence that supports the first hypothesis.

For both men and women, there was no trend for employment status at both locations, and there was no trend for work at different locations for men and women. Beyond the definitions, another reason is that women have increased their full-time work over the past decade. The gradual decline of the red dashed line maybe because it is easier for women to find a full-time job at home.

Figure 6: Hypothesis 1: Trends of Employment Status for Each Gender and at Each Location of Work. 


\section{International Academic Conference on Management \& Economics}

8 - 10 No

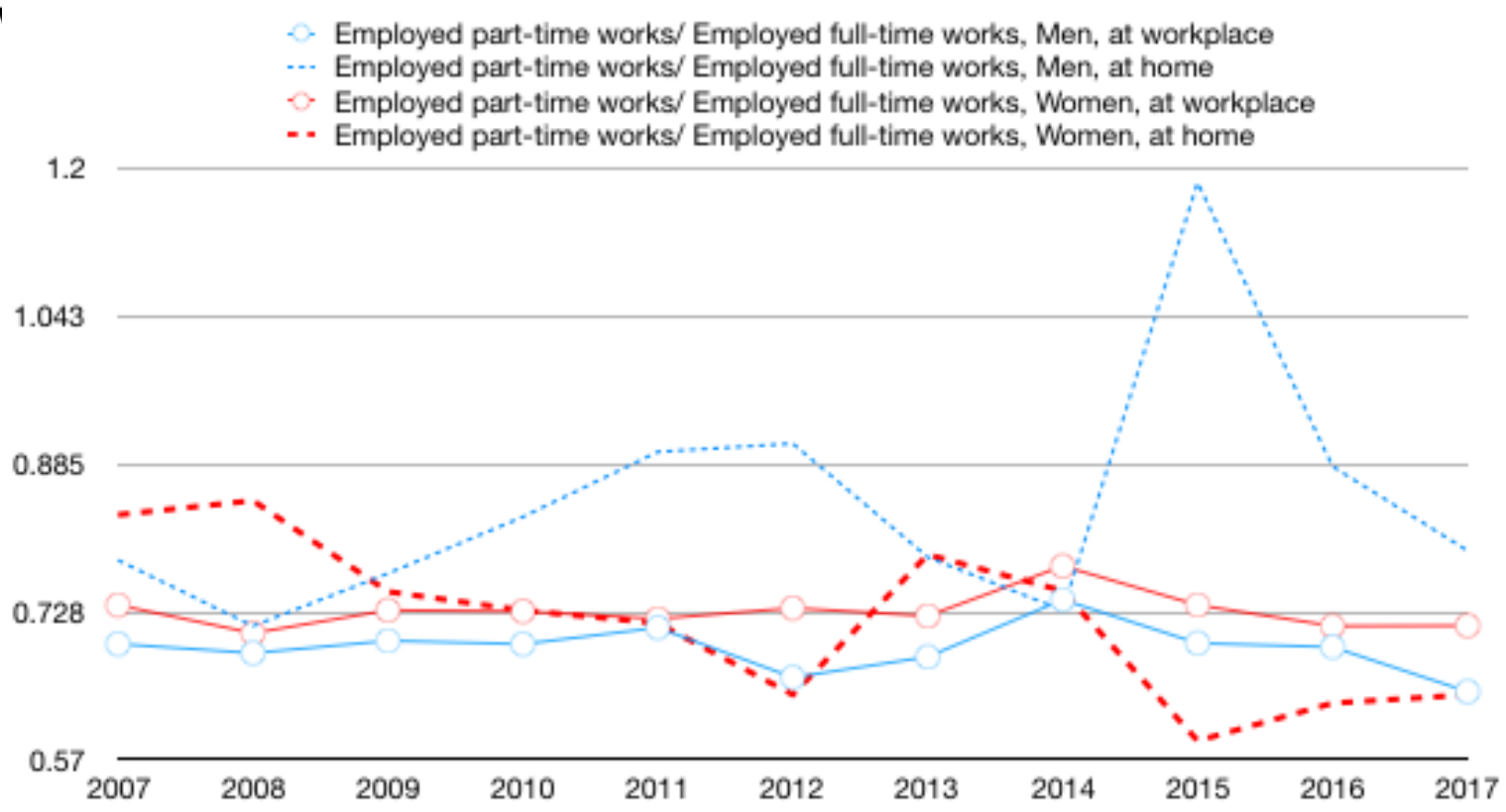

ource: Data is from Data is from American Time Use Survey.

After comparing the ratio of employed as part-time workers to as full-time workers for each gender at each working place, the ratio for the location of work alone is also needed. If it indicated that the working hours of part- time workers at home have a relative increase compared with that of full-time workers, the figure is consistent with the hypothesis. However, there was no significant change in the number of hours worked by part-time workers in the workplace compared to full-time hours at home though there was a gradual decrease in the ratio of hours worked by part-time workers to full-time workers working from home. This can be explained by the fact that more and more full-time jobs have been created, so many people who work from home choose to apply for a full-time job.

Figure 7: Hypothesis 1: Trends of Employment Status at Different Locations. 


\section{International Academic Conference on Management \& Economics}

8 - 10 Nor

Working part-time work/ Working full-time works, at workplace

Working part-time work/ Working full-time works, at home

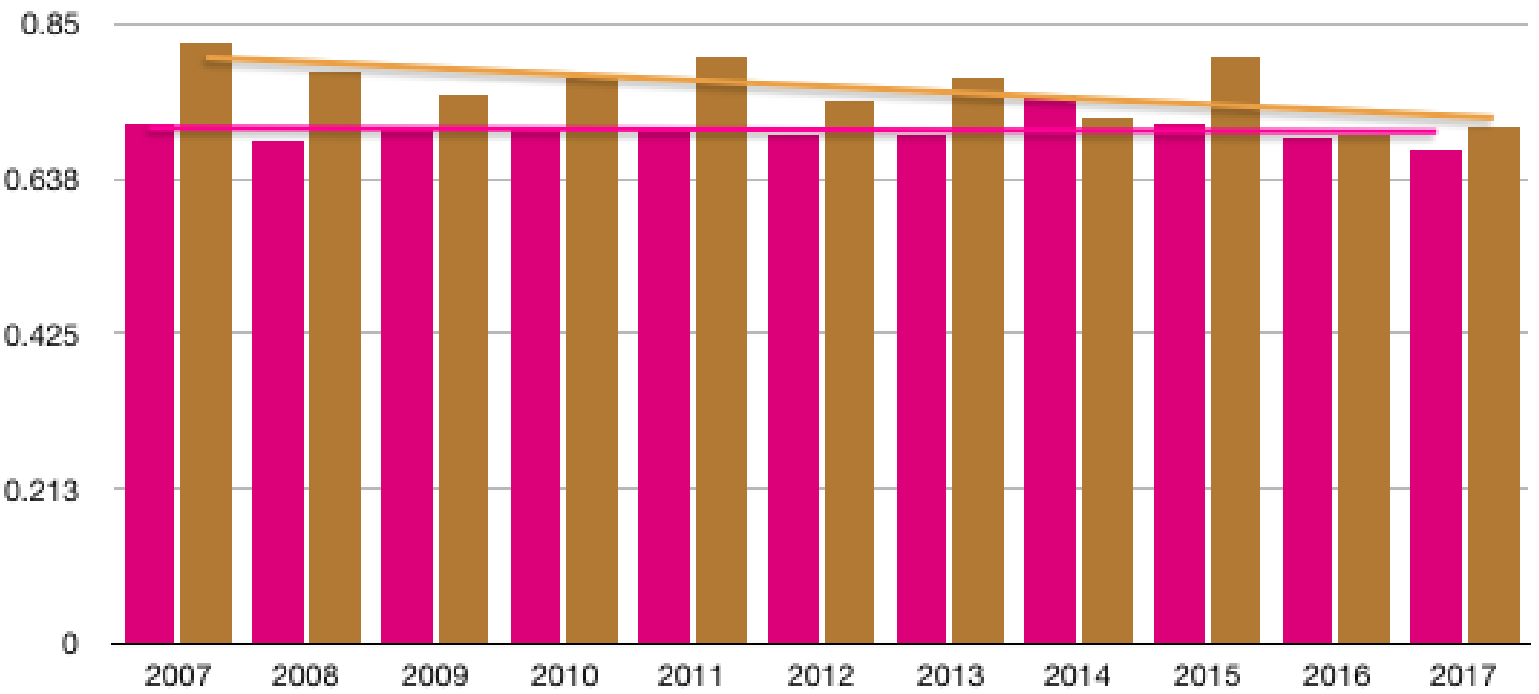

Source: Data is from Data is from American Time Use Survey.

\subsection{Hypothesis 2. The location of work shift from work- place to home}

We use the ratio of the average time of working at home versus at workplace as an indicator of work flexibility in terms of location of work. The most straightforward analysis is for the whole population, as shown in figure 8 . The chart presents a very clear upward trend toward work flexibility with respect to the location of work. Over the entire period, the time worked at home relative to workplace has been rising for the whole population. One of the reasonable drivers of this trend may be the development of the gig economy in the same period. Over time, there are more chances for people to work from home instead of working at workplace.

Figure 8: Hypothesis 2: Aggregate Trend for Locations of Work. 


\section{International Academic Conference on Management \& Economics}

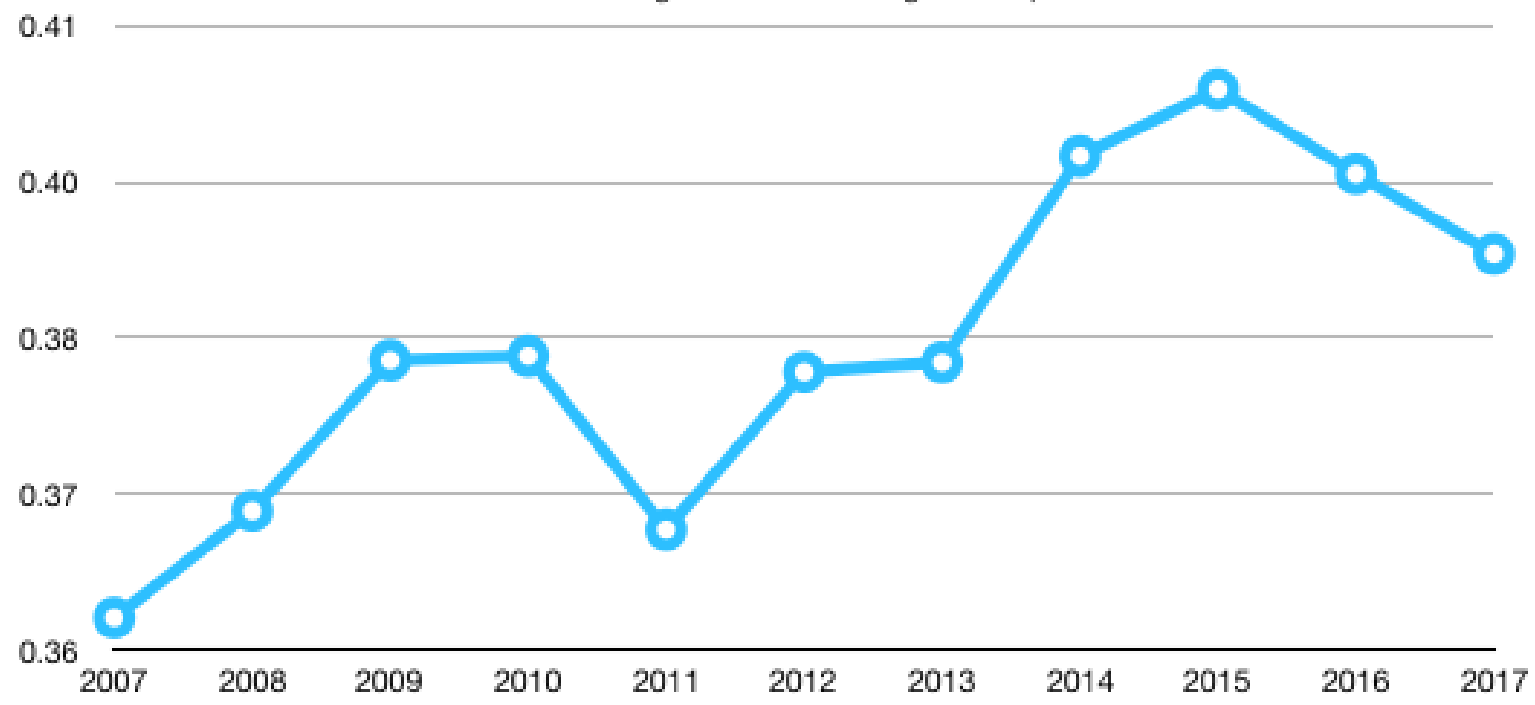

Source: Data is from Data is from American Time Use Survey.

It is worth checking whether the flexibility toward work at home is particularly significant for women, since the female workers, for demands such as for maternity and child-care tend to have a stronger preference for work flexibility. If so, one may expect that the ratio of average hours of working at home to working at workplace for women increased more significantly than for men. As shown in figure 9, the home/workplace ratios for both women and men increased, although not in a monotonic manner. This situation happened maybe because there are many women who need to take care of their families now have the opportunities to work from home, in other words, there are more occupations that have been created due to the rise of the gig economy.

Figure 9: Hypothesis 2: Trends of Locations of Work for Each gender. 


\section{International Academic Conference on Management \& Economics}

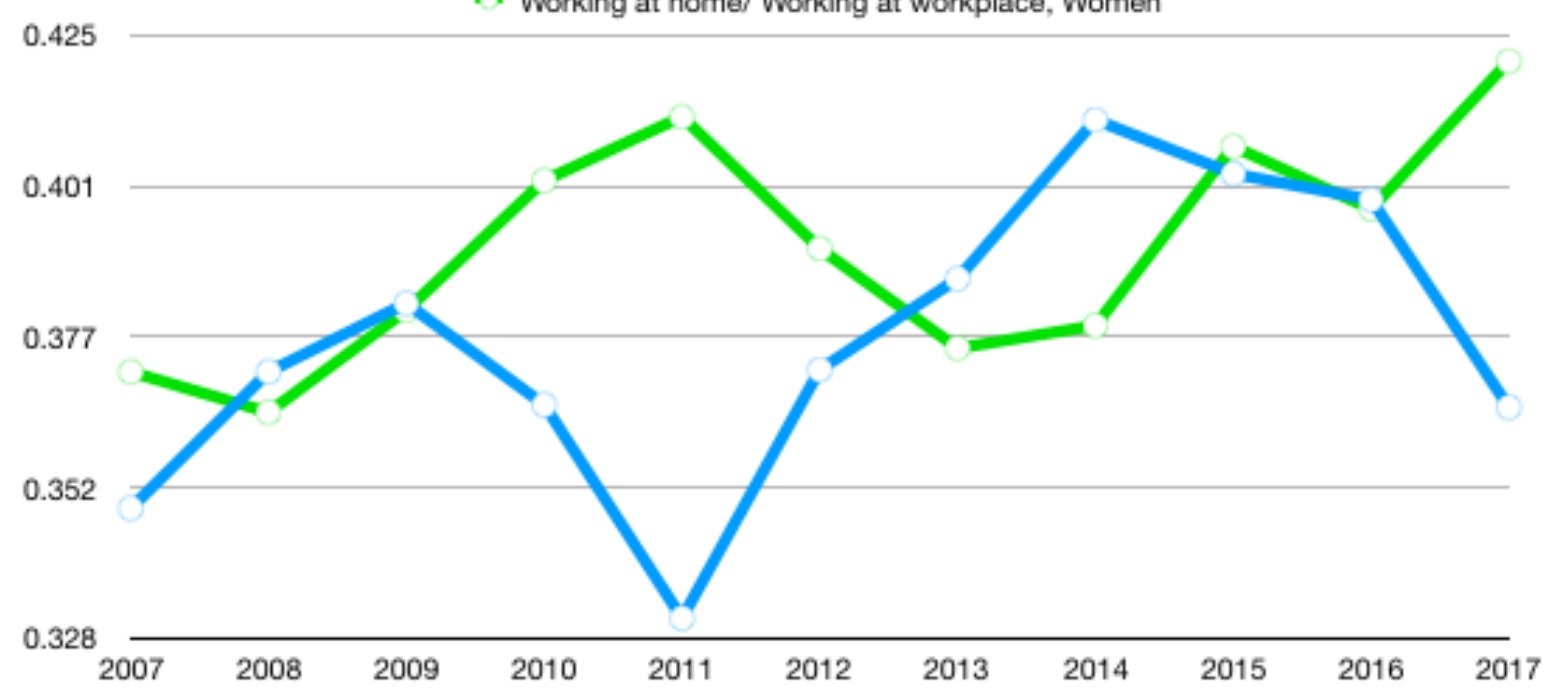

Source: Data is from Data is from American Time Use Survey.

After categorizing people into two groups by gender, separating workers into wage and self-employed workers is another way to compare the data. As elaborated more in the third hypothesis of this paper, the type of workers is an important indicator of the effectiveness of the rise of the gig economy for changing the way people work. In the past, wage and self-employed workers used to work at workplace, while it is possible that recently both types of workers are not subject to geographic constraints. And in addition, as the self-employment in nature was more flexible in location throughout the period, a shift toward flexibility of location being more salient for wage-salary work may provide evidence for the impacts of the gig economy. As shown in figure 10, indeed, the trend toward work at home is particularly noticeable for wage- salary workers, while that for self-employed work stays relatively constant over the time period. There are more opportunities for wage-salary worker to work at home.

Figure 10: Hypothesis 2: Trends of Locations of Work for Different Types of Work. 


\section{International Academic Conference on Management \& Economics}

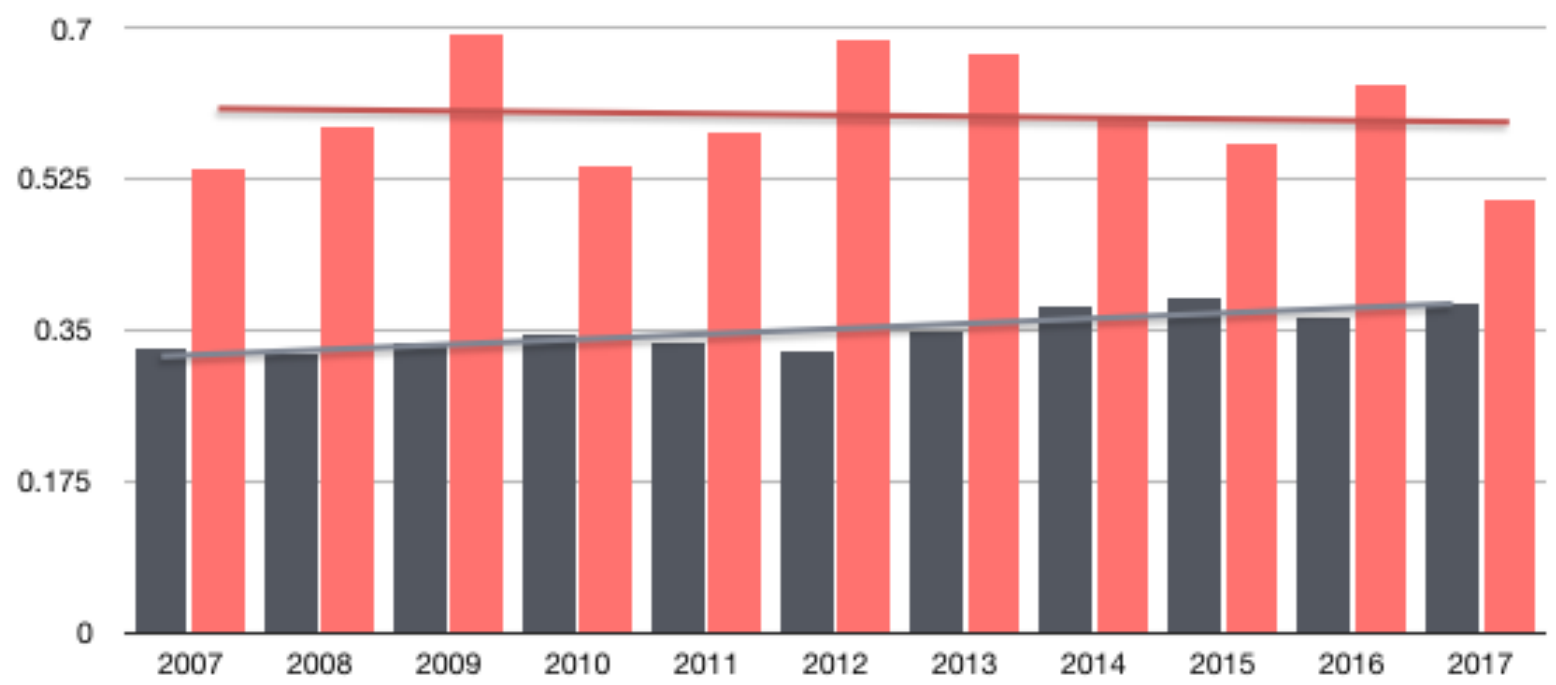

Source: Data is from Data is from American Time Use Survey.

The shift to working at home may also differ in terms of employment status. Again, the idea is that given the full-time job is more constrained by location than a part-time job in the first place, a relative rise in the ratio for a full-time job is strong evidence for my second hypothesis. According to figure 11, this is shown to be indeed the case. The ratio for full-time workers increased over the entire period, while the ratio for part-time workers stays stable.

Figure 11: Hypothesis 2: Trends of Locations of Work for Different Employment Status.

* Working at home/ Working at workplace, Part-time workers

- Working at home/ Working at workplace, Full-time workers

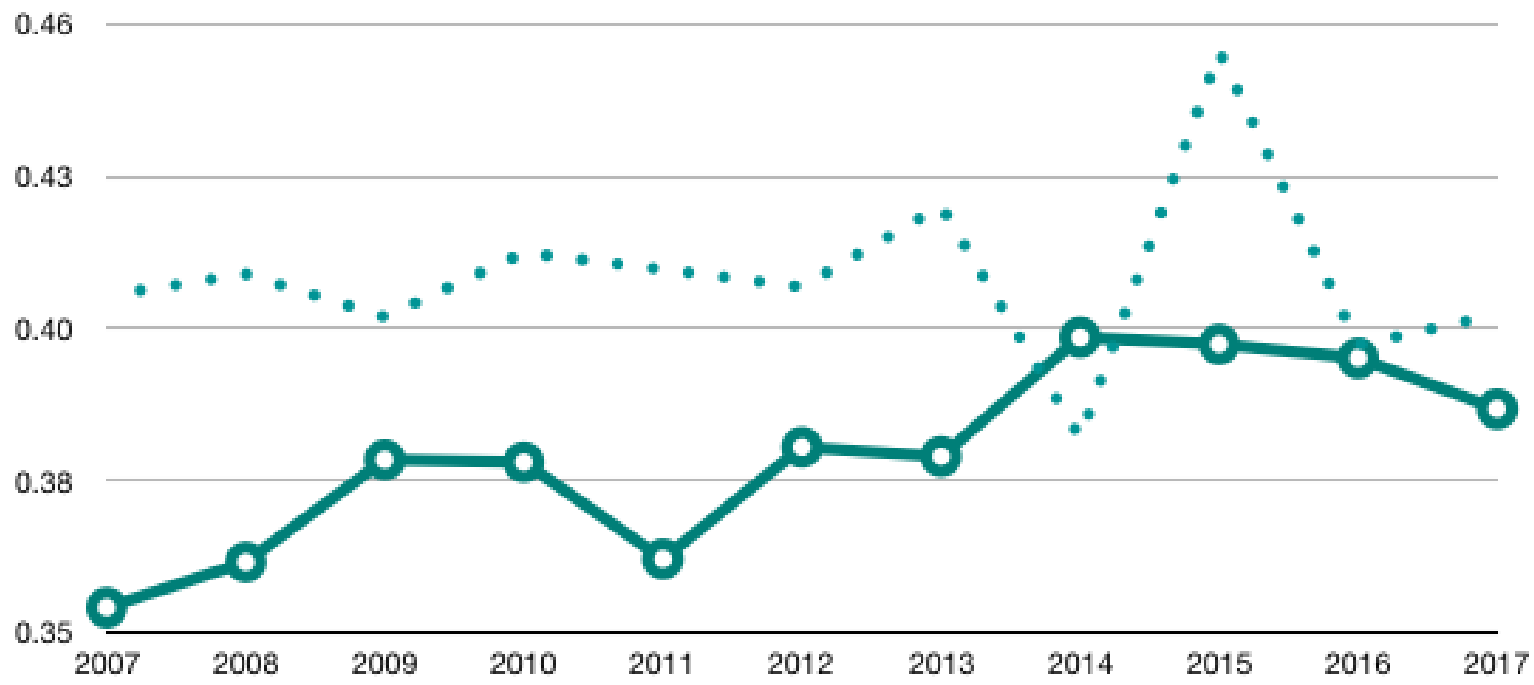

Source: Data is from Data is from American Time Use Survey.

\subsection{Hypothesis 3. The type of work shift from salary worker to self-employment}




\section{International Academic Conference on Management \& Economics}

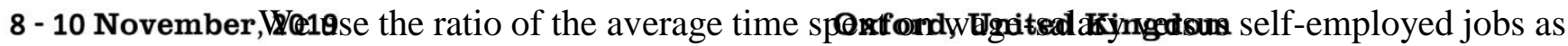
an indicator of flexibility in terms of the type of work. To find out the ratio of the average hours spent by self-employed workers to that of wage workers over the past decade is necessary to test the third hypothesis. The overall trend for the whole American population is also the first step, and the goal is to explore whether more time is spent on self-employment jobs than salaried jobs. Figure 12 shows that there is, if any, a decline of self- employment versus a wage-salary job. So in the aggregate level, there is no evidence that the gig economy facilitates flexibility in terms of employment status.

Figure 12: Hypothesis 3: Aggregate Trend of Types of Work

Self-employed/ Wage workers

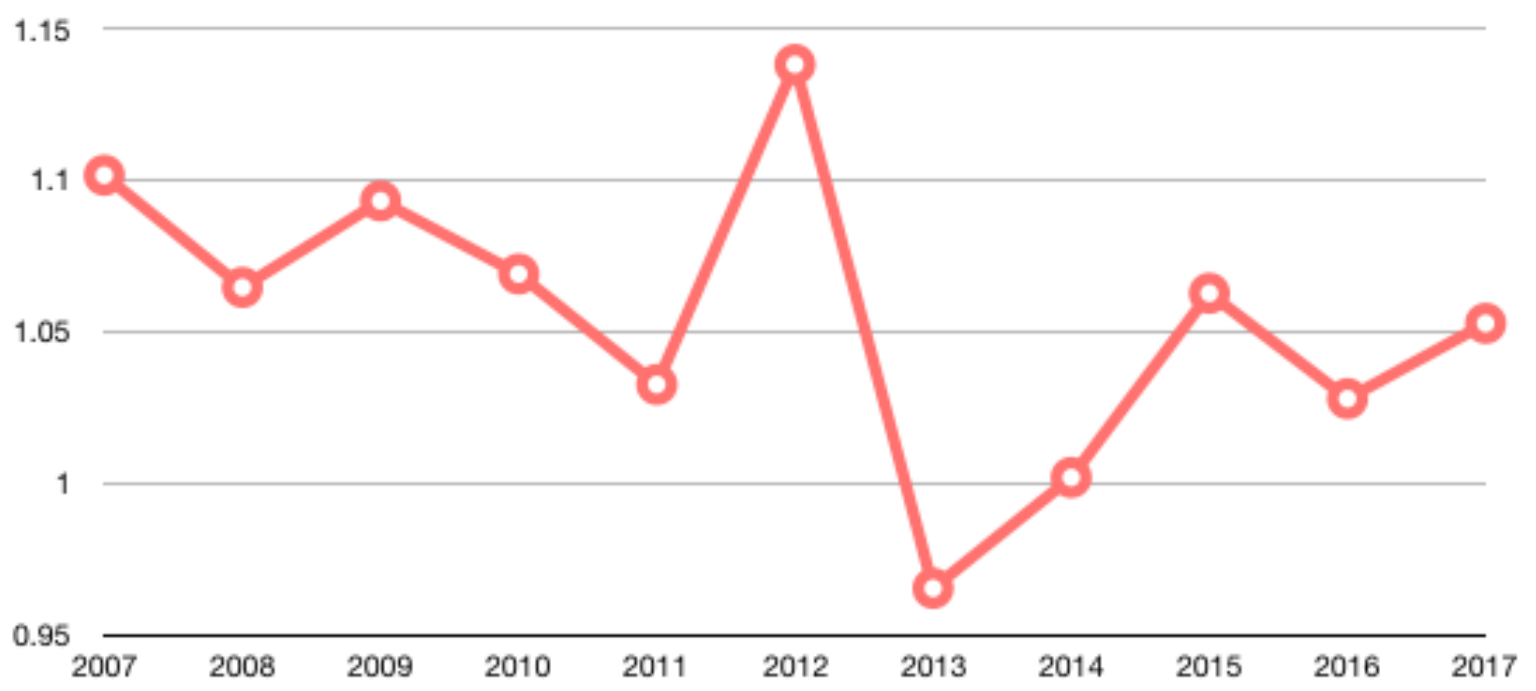

Source: Data is from Data is from American Time Use Survey.

It is possible that the shift toward self-employment differs in terms of location. Figure 13 plots the ratios for work at home and at work place, separately. For the workplace-based job, there is no structural change in the type of job over the period, while for the home-based job, there is a decrease in the ratio, thus a rise in the time of wage-salary work. Although this may seem to be the opposite of what we expect, it actually supports our hypothesis if it is interpreted as that home-based work has been more compatible with wage-salary work compared to in the past. Conditional on the preference of working at home, the increasing availability of positions offered by an employer may be an outcome of the gig economy.

Figure 13: Hypothesis 3: Trends of Types of Work at Different Locations of Work. 


\section{International Academic Conference on Management \& Economics}

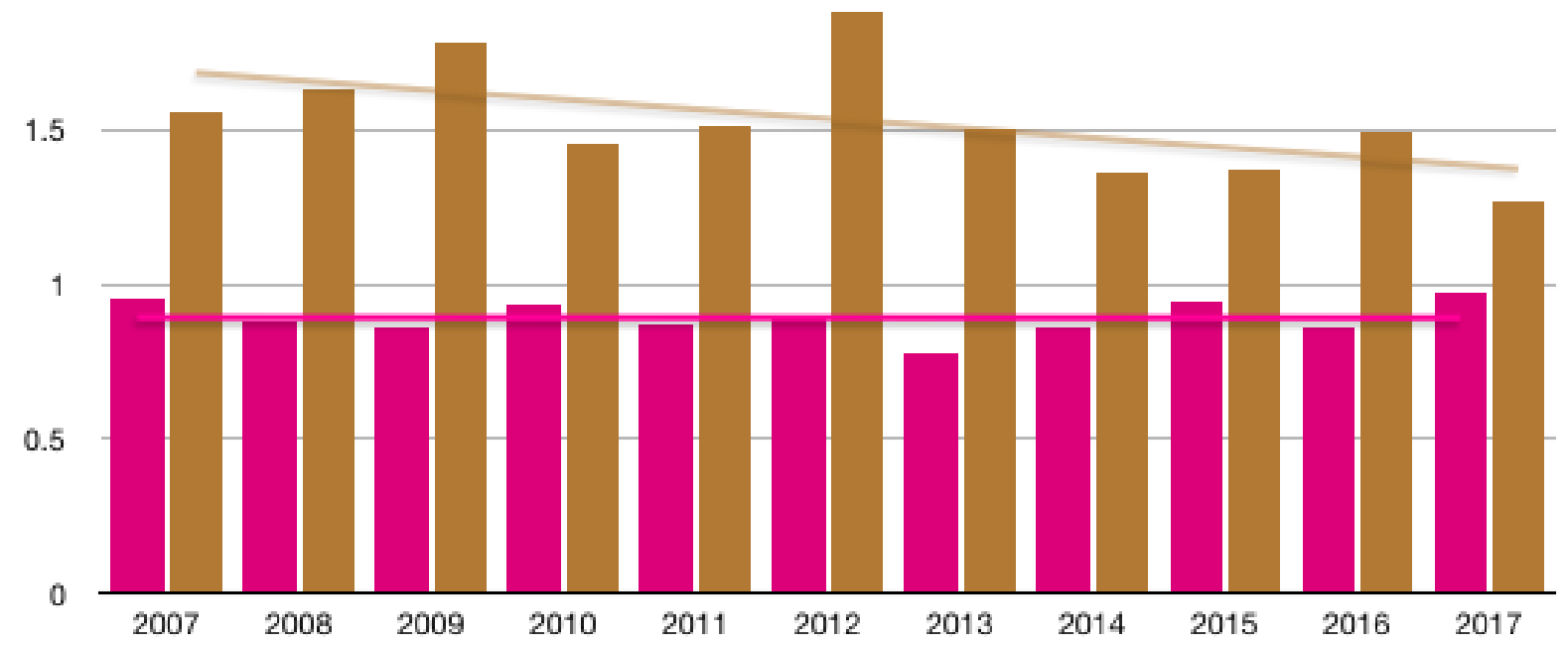

Source: Data is from Data is from American Time Use Survey.

In general, after summarizing these charts, some positive conclusions could be drawn.

First, women tend to prefer a more flexible work arrangement that they work at home more over the period, 2007 to 2017. According to the figure, the ratio of time spent working at home to time spent working at workplace for women increased significantly in 2017 compared to 2007, reflecting a decade in which more women are working at home.

Second, peoples work location is more flexible in that people work at home more relative to working at the workplace is shown to be true. The ratio of the number of hours wage workers work at home to the number of hours wage workers work at workplace increased, along with the ratio of working at home to working at workplace increased. The amount of time wage workers spend working at home increases relative to the amount of time wage workers spend working at workplace.

Third, it is proved that among those people who work at home, they more easily work for full-time, which means more full-time jobs are created by the rise of the gig economy. The ratio of working at home to working at workplace for full-time workers increased over the period, which may suggest that the full-time workers can work at home more easily, and they tend to prefer work from home compared to work at workplace. There are more salary jobs are held at home, and workers have more choices at home that they could earn income by wage workers at home.

While on the other hand, some data are contrary to the idea of this paper. The ratio of women employed part-time works to employed full-time works at home decreased and the relative hours of employed part-time works at home decreased respectively. This may because, with the development of the gig economy, more full-time jobs are created at home, so women have more choices to work from home. And perhaps the length of time and number of part-time jobs at home grow less than the length of full-time work, so this ratio is declining.

In 2015, there was a sudden increase in the number of hours men worked part-time at home, but with limited evidence to explain this. In addition, the fluctuations always happen between 2014 and 2015, but the explanation is not found. 


\section{International Academic Conference on Management \& Economics}

\section{8 - 10 NołmGérn?et?sion}

Oxford, United Kingdom

Overall, work-at-home has become more common over the past ten years among the U.S. labor force, according to ATUS macro data from 2007 to 2017. And what is more interesting is that the shift is the most obvious among female workers who are in nature more inclined to choose flexible work arrangements. In addition, there is an increase in the proportion who works at home compared to at workplace in relation to the formal jobs such as full- time jobs and wage-salary workers. These changes might be best explained by the ongoing development of the gig economy.

In the same time, there is thus far no conclusive evidence that the rise of the gig economy has shifted labor force from full-time job to part-time job. Neither has it been evident from the aggregate data that self-employment has taken a greater share than a wage salary job. This suggests we should not overstate the changes caused by the gig economy in terms of its macroeconomic impacts.

Admittedly, there are a number of limitations in this paper. For example, this paper only used time-series data for aggregate labor forces. This ignores the microeconomic heterogeneity across individuals and households that are involved in the labor supply decision. A more in-depth analysis requires one to work with household-level data. This will be the next step of my research.

\section{References}

(Abraham et al., 2012)

(Duca, 2018) 


\section{International Academic Conference on Management \& Economics}

8 - 10 Noven(bem gestribrahim, 2017)

Oxford, United Kingdom

(Farrell \& Greig, 2016)

(Freedland \& Prassl, 2017)

(Gardiner, 2015)

(Goldschmidt \& Schmieder, 2017)

(Robles \& McGee, 2016)

\section{References}

[1] Abraham, K. G., Haltiwanger, J. C., Sandusky, K., \& Spletzer, J. R. (2018). Measuring the gig economy: Current knowledge and open issues (No. w24950). National Bureau of Economic Research.

[2] Dong, Jing, and Rouba Ibrahim. "Managing Supply in the On-Demand Economy: Flexible Workers or Full-Time Employees?." Available at SSRN 2971841 (2017).

[3] Duca, J. V. (2018). Inflation and the Gig Economy: Have the Rise of Online Retailing and Self-Employment Disrupted the Phillips Curve?.

[4] Farrell, D., \& Greig, F. (2016). Paychecks, paydays, and the online platform economy: Big data on income volatility. JPMorgan Chase \& Co. Institute.

[5] Freedland, M. R., \& Prassl, J. (2017). Employees, Workers, and the'Sharing Economy': Changing Practices and Changing Concepts in the United Kingdom.

[6] Gardiner, L. (2015). Does the gig economy revolutionise the world of work, or is it a storm in a teacup? The Economist, Oct, 23.

[7] Goldschmidt, D., \& Schmieder, J. F. (2017). The rise of domestic outsourcing and the evolution of the German wage structure. The Quarterly Journal of Economics, 132(3), 1165-1217.

[8] Robles, B. J. and McGee, M. (2016). Exploring online and offline informal work: findings from the enterprising and informal work activities (eiwa) survey. 